\title{
COMPARATIVE STUDIES OF DIFFERENT EXTRACTION METHODS OF ESSENTIAL OIL FROM MATRICARIA RECUTITA L. IN IRAN
}

\author{
SEYED SAIED HOMAMI*1; KAMKAR JAIMAND ; MOHAMMAD BAGHER REZAEE ${ }^{2}$ AND \\ REZA AFZALZADEH ${ }^{3}$ \\ ${ }^{1}$ Islamic Azad University, South Tehran branch, Tehran, Iran. \\ ${ }^{2}$ Phytochemistry Group, Department of Medicinal Plants \& By-products, Research Institute of Forest and Rangelands, P.O.Box 1318, Tehran, Iran. \\ ${ }^{3}$ Faculty of physic, Industry Khajeh Naseer Toosy University of Technology, Tehran, Iran.
}

\begin{abstract}
Chamomile, Matricaria recutita L. from family of Asteracae, is a well-known medicinal plant in folk medicine cultivated all over the world. Chamomile

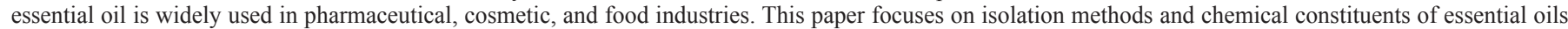

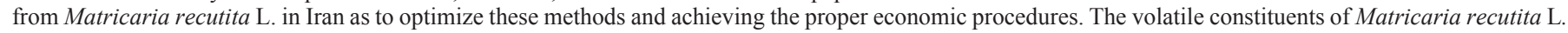

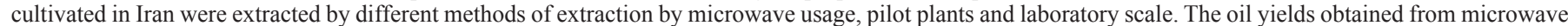

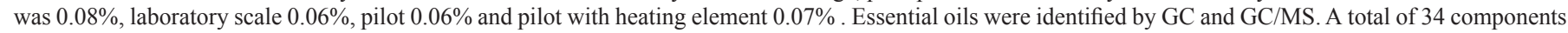

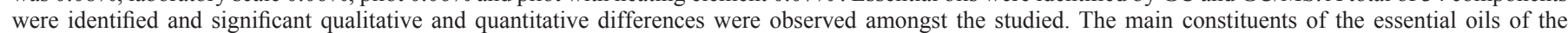

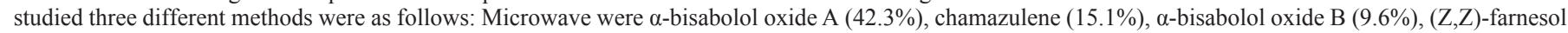

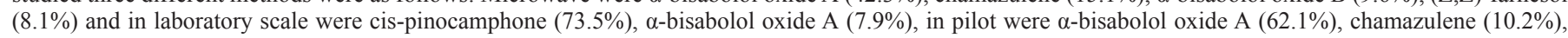

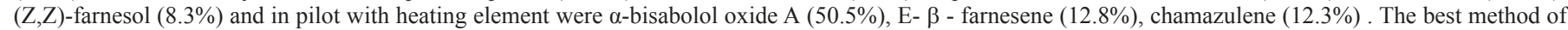

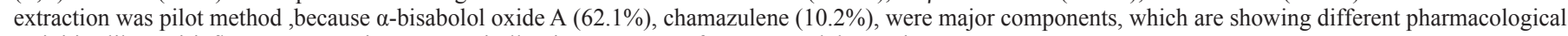
activities like anti-inflammatory, anti-cancer, anti-allergic, a treatment for stress and depression.
\end{abstract}

Key words: Matricaria recutita L. (M. chamomilla L.), chamomile, volatile oil SDE extract, GC/FID, GC/MS.

\section{INTRODUCTION}

Matricaria chamomilla L. (syn: M. recutita L.; German chamomile) resides in the Asteraceae (Compositae) family and is one of the most widely used medicinal plants in the world. Chamomile essential oil is widely used in pharmaceutical, cosmetic, and food industries. The pharmacological effect of chamomile is mainly connected with its essential oil for its spasmolytic, antimicrobial, and dis-infective properties. The biologically active substances in chamomile essential oil are $\alpha$-bisabolol, bisabolol oxides, chamazulene, and en-yne- dicycloethers [1-5].

The plant is an annual herb with erect branching and finely divided leaves growing between $50-90 \mathrm{~cm}$ tall. The flowers are daisy-like, with hollow conical yellowish centre surrounded by silver-white to cream colored florets M. chamomilla $\mathrm{L}$. is a safe plant and is used in different commercially available forms such as tea, infusion, liquid and capsules in human nutrition. It has a stable natural monocyclic sesquiterpene alcohol named $\alpha$-bisabolol as the main component, so the plant essential oil has a long shelf life of 6 to 24 months. In addition to the high stability and safety points, the plant has no proven potentially toxic compound and therefore, no acute toxicity for human and animals [15]. Consequently, it has been listed as GRAS by the FDA $[14,15]$.

Different essential oil isolation techniques (hydro-distillation [2,3,5,7], supercritical fluid extraction [6,8,9,10,11], headspace analysis [4 ] ) have been applied for studying the volatile constituents of chamomile by several investigators. Different analytical techniques were in the literature for the qualitative and quantitative assessment of the oil. These include elemental micro-analysis, liquid sampling mass spectrometry (LS/MS), TLC, GC/MS. In addition, an enantioselective HPLC method was developed for the separation of the four stereoisomers of $\alpha$-bisabolol and a RP-HPLC method was reported to separate the isomeric en-yne-dicycloethers and chamazulene. (E)- $\beta$-Farnesene, $\alpha$-bisabolol, bisabolol oxide $\mathrm{A}$ and $\mathrm{B}$, chamazulene, and en-yne-dicycloethers were found to be the main constituents in chamomile oil [2-11].

Comparison of different methods in extraction of essential oils from aromatic plants, Matricaria recutita L. in Iran, as to optimize extraction methods and examine the compositions of the oil during hydro-distillation were the main goals of this research. Qualitative and quantitative achievements for their values in the economical methods were of concerned.

\section{EXPERIMENTATIONS}

\section{Plant material}

Matricaria chamomilla L. was collected during June -July 2011 from Esfahan province, central of Iran, plant specimen determined by Iranian Botanical Garden(IBG) staff. voucher number MPH. 531. Plant materials (flowers) were extracted by three different apparatus .

\section{MADH apparatus and procedure}

The home-made microwave extraction apparatus is depicted in Fig.1. Microwave-assisted hydro-distillation (MAHD) was purchased from Feller Germany microwave apparatus Model MW 420 GS. The multimode microwave reactor has a rated voltage $220-240 \mathrm{~V} \sim 50-60 \mathrm{~Hz}$, rated input power Microwave $1550 \mathrm{~W}$, rated output power Microwave $1100 \mathrm{~W}$, rated input power( Grill) 1200-1400 W, oven capacity $42 \mathrm{~L}$, turntable diameter $345 \mathrm{~mm}$, external dimensions (LxWxH) 553 x 465 x $326 \mathrm{~mm}$. Temperature was controlled by feedback to the microwave power regulator.

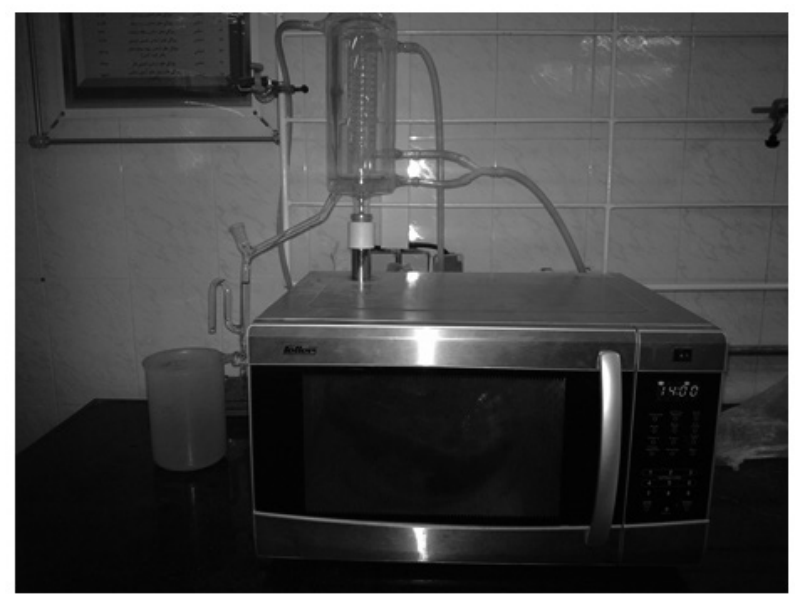

Fig. 1 - Microwave-assisted hydro-distillation apparatus used in this study.

Isolation of essential oil

Dried aerial part biomass ( $80 \mathrm{~g}$ per sample) of chamomile was extracted 
by different methods and apparatus like hydro-distillation extraction on microwave, pilot plants and laboratory scale. The distillation time was $3 \mathrm{~h}$ at a rate of $3-4$ $\mathrm{mL} / \mathrm{min}$. The oils were separated from the water by decantation and were dried by filtration over anhydrous sodium sulfate. The oils were stored prior to analysis in ampoules in a refrigerator at $4{ }^{\circ} \mathrm{C}$, and were analyzed within a week. The averaged oil yields obtained from microwave system was $0.08 \%$, laboratory scale was $0.06 \%$, pilot was $0.06 \%$ and pilot with heating element was $0.07 \%$, then the essential oils were identified by GC and GC/MS.

Table.1 : Results of three different methods of extracting Oils from Matricaria chamomilla.

\begin{tabular}{|c|c|c|c|c|c|}
\hline \multirow{2}{*}{ Compounds } & \multirow{2}{*}{ R.I $I^{a}$} & \multicolumn{4}{|c|}{ Method of Extraction } \\
\hline & & Microwave & $\mathrm{Lab}$ & Pilot & Pilot-element \\
\hline Sabinene & 969 & --- & 2.14 & --- & --- \\
\hline$\beta$-Pinene & 985 & --- & --- & 0.54 & --- \\
\hline (E )- $\beta$-Ocimene & 1058 & --- & --- & 0.34 & --- \\
\hline$\gamma$-Terpinee & 1068 & --- & --- & 1.21 & --- \\
\hline Cis-Pinocamphone & 1176 & --- & 73.54 & --- & --- \\
\hline p-Cymen-9-ol & 1205 & --- & 3.50 & --- & --- \\
\hline Cis-Carvone oxide & 1262 & --- & 0.72 & --- & --- \\
\hline Cis-Dihydr- $\alpha$ - terpinyl acetate & 1315 & --- & 3.46 & --- & --- \\
\hline E-Caryophyllene & 1419 & --- & --- & --- & 0.41 \\
\hline E- $\beta$-Farnesene & 1463 & 4.67 & 1.24 & 2.17 & 12.87 \\
\hline (Z)- $\gamma$-Bisabolene & 1512 & --- & --- & --- & 1.00 \\
\hline (E)- $\gamma$-Bisabolene & 1547 & --- & 0.55 & --- & --- \\
\hline Germacrene B & 1553 & --- & 0.82 & --- & 0.44 \\
\hline n-Tridecanol & 1570 & 1.62 & --- & 0.27 & 0.81 \\
\hline Spathulenol & 1576 & 0.75 & --- & --- & --- \\
\hline Dihydro(10,11)-ar- $\alpha$-bisabolol & 1607 & 0.75 & --- & 0.31 & --- \\
\hline$\alpha$-Bisabolol oxide $B$ & 1650 & 9.58 & 1.27 & 5.67 & 5.24 \\
\hline E-Bisabol-11-ol & 1664 & 1.05 & --- & --- & --- \\
\hline$\beta$-Bisabolol & 1671 & 1.86 & --- & 0.41 & 0.68 \\
\hline$\alpha$ - Bisabolone oxide $\mathrm{A}$ & 1679 & 0.99 & --- & 0.48 & --- \\
\hline$\alpha$-Bisabolol & 1693 & 0.61 & --- & 0.21 & 0.37 \\
\hline (Z,E)-Farnesyl acetate & 1701 & --- & --- & -- & 0.28 \\
\hline$(\mathrm{Z}, \mathrm{Z})$ - Farnesol & 1718 & 8.14 & 1.14 & 8.30 & 5.82 \\
\hline (E,E)-Farnesol & 1725 & 2.57 & --- & 1.22 & 2.87 \\
\hline (E,E)-Farnesyl acetate & 1726 & 0.98 & 0.45 & 1.82 & 1.52 \\
\hline Chamazulene & 1732 & 15.08 & 1.67 & 10.25 & 12.33 \\
\hline (E,Z)-Farnesol & 1746 & 2.27 & --- & 1.03 & 1.92 \\
\hline$\alpha$-Bisabolol oxide $\mathrm{A}$ & 1755 & 42.27 & 7.97 & 62.16 & 50.50 \\
\hline 2,7(14),10-Bisabolatrien-1-ol-4-one & 1850 & 3.19 & --- & 0.98 & 2.11 \\
\hline n-Hexadecanol & 1878 & --- & --- & -- & 0.76 \\
\hline n-Nonadecane & 1893 & --- & 1.46 & 0.38 & --- \\
\hline Not identified & 1961 & 3.55 & --- & 1.09 & -- \\
\hline 1-Eicosene & 1995 & --- & --- & 0.56 & --- \\
\hline n-Octadecanol & 2088 & --- & --- & 0.50 & --- \\
\hline
\end{tabular}

${ }_{\mathrm{a}}$ R.I. $=$ retention indices on DB-5 column

Gas Chromatography :

$\mathrm{GC}$ analysis was performed on a Shimadzu $15 \mathrm{~A}$ gas chromatograph equipped with a split/ non-split injector and a flame ionization detector (FID) at $250^{\circ} \mathrm{C}$. $\mathrm{N}_{2}$ was used as a carrier gas $(1 \mathrm{ml}$ min- 1$)$ and a DB-5 type was utilized as the capillary $(50 \mathrm{~m} \times 0.2 \mathrm{~mm}$, film thickness $0.32 \mu \mathrm{m})$. Temperature within the column for 3 min was retained at $60^{\circ} \mathrm{C}$, after that the column was heated at a rate of $5^{\circ} \mathrm{C}$ min- 1 until it reached at $220^{\circ} \mathrm{C}$ and maintained in this condition for 5 min. The split ratio was 1:100. 


\section{Gas Chromatography - Mass Spectrometry :}

The GC/MS unit consisted of a Varian Model 3400 gas chromatograph which was coupled to a Saturn II ion trap detector was used. The column was the same as GC, and the GC conditions were as above. Mass spectrometer conditions were : ionization potential $70 \mathrm{eV}$; electron multiplier potential is $2000 \mathrm{~V}$.

The identity of the oil components were established from their GC retention indices, relative to $\mathrm{C}_{7}-\mathrm{C}_{25} \mathrm{n}$-alkanes, by comparison of their MS spectra with those reported in the literature (16), (17), (18), and by computer matching with the Wiley 5 mass spectra library, whenever possible, by coinjection with standards available in the laboratories.

\section{RESULTS AND DISCUSSION}

For both hydro-distillation laboratory scale and microwave-assisted hydro-distillation, the extraction temperature was equal to the boiling point of water under the conditions of the study $\left(\sim 100^{\circ} \mathrm{C}\right)$. The oil yields obtained from 80 grams of samples plant by microwave-assisted hydro-distillation was $0.08 \%$, hydro-distillation laboratory scale was $0.06 \%$, pilot was $0.06 \%$ and pilot with element was $0.07 \%$. To reach such temperature level, where the actual distillation started, it was necessary to heat the samples for only 15.0 minutes with microwave-assisted hydro-distillation, while 38 minutes was necessary in the case of hydro-distillation laboratory scale. This was due to the more efficient microwave heat flow. According to the Table.1, components in hydro- distillation laboratory scale are completely different with microwaveassisted hydro-distillation, pilot and pilot with heating element.

For example in hydro-distillation laboratory scale main compound was cis-pinocamphone $(73.5 \%)$, but in other methods this was not observed.

Main component in microwave-assisted hydro-distillation, pilot and pilot with element was $\alpha$-bisabolol oxide A $42.27 \%, 62.16 \%$ and $50.50 \%$, respectively, and the same compound in hydro-distillation laboratory scale was $7.97 \%$.

Another compound was chamazulene which was $15.08 \%, 10.25 \%$ and $12.33 \%$, respectively, but in hydro-distillation laboratory scale this was $1.67 \%$. Also for (Z,Z)-farnesol compound in microwave-assisted hydro-distillation , pilot and pilot with heating element was $8.14 \%, 8.30 \%$ and $5.82 \%$, respectively, but in hydro-distillation laboratory scale is $1.14 \%$.

When our results were compared with other reports, the extraction, behaviors depending on the different conditions used. Golmakani and Rezaei (2008a, b) also reported similar results for the extraction yield of essential oils from Thymus vulgaris L. and Zataria multiflora Boiss. obtained by hydrodistillation and microwave-assisted hydro-distillation $[19,20]$. Final extraction yield of hydro-distillation after 240 minutes $(4.18 \%$, w/w) was statistically similar to those obtained by microwave at 180,360 , and $540 \mathrm{~W}$ after 210 , 150 , and 120 minutes, respectively. As final extraction yield results indicated, microwave-assisted hydro-distillation could decrease the time required for obtaining the same amount of essential oil by about $50 \%$ compared to hydrodistillation, i.e. 120 minutes instead of 240 minutes.

These results are in good agreement with the results of Stashenko et al. (2004) for Colombian Xylopia aromatica. They found that for the same extraction yield, the time required for microwave-assisted hydro-distillation was one-fourth of that for hydro-distillation [21]. Rezvanpanah et al. (2008), extracted essential oils from Satureja hortensis and Satureja montana using microwave-assisted hydro-distillation, where the extraction time was reduced significantly as the microwave power was changed from 220 to $660 \mathrm{~W}$. The difference in the extraction yield at 180 and $540 \mathrm{~W}$ seemed to be more pronounced during the first 2 hours of extraction. The required time to reach the boiling point of water at $540 \mathrm{~W}$ was nearly one-fourth of that at $180 \mathrm{~W}$. After 20 minutes of operation, the extraction yield at $540 \mathrm{~W}(1.53 \%, \mathrm{w} / \mathrm{w})$ was about five times more than that at $180 \mathrm{~W}(0.31 \%$, w/w). Meanwhile, the extraction yield for $540 \mathrm{~W}$ after 45 minutes of operation was the same as that obtained in 60 minutes at $360 \mathrm{~W}$ [22]. In another study, Özek et al. (2005) extracted essential oils of three endemic Turkish Heracleum species by different techniques. Their results indicated some quantitative differences amongst some of the extracted components. The microwave-assisted hydrodistillation extracted oils showed slightly lower amounts of octyl acetate which was $59 \%$ compared to those extracted by hydro-distillation and other extraction techniques which was $93.7-94.9 \%$ [23]. Instead, some other compounds were extracted at higher levels when using microwave-assisted hydro-distillation .

Compared to hydro-distillation, no new compound was found in the essential oils extracted by microwave-assisted hydro-distillation in the current study. These results indicated that using microwave did not influence the quality of the extracted essential oil, but the extraction time was shorter. Similar findings were reported by Golmakani and Rezaei (2008a) for the compositions of essential oils extracted with hydro-distillation [ thymol (37.20\%), p-cymene $(16.85 \%), \gamma$-terpinene $(9.06 \%)]$ and microwave-assisted hydro-distillation [ thymol (40.20\%), p-cymene (17.57\%), $\gamma$-terpinene $(8.54 \%)$ ] from Thymus vulgaris L [19].

\section{ACKNOWLEDGMENTS}

Authors are thankful to Islamic Azad University (South Tehran Branch) for the financial support .

\section{REFERENCES}

1.- T.Koppel, E. Arak, E. Türi, Eesti Rohuteadlane, 3 ,107-109,(1993)

2.- E.H.Arak, Results of essential oil analysis of pineapple food and wild chamomile by gas chromatographic method. . In Abstract Book of II Congress of Estonian Pharmacists. Tallinn, (1981),79-80.

3.- E.H. Arak, T.T. Pehk, U.J. Mäeorg, V. E. Vahar, T.M. Altsaar, Isolation of spathylenol from essential oil of wild chamomile and its identification. In Abstract Book of II Congress of Estonian Pharmacists. Tallinn, 1981: (1981), pp. 84-87 (in Russian).

4.- E.J. Brunke, E.J.Hammerschmidt, G. Schmaus, Headspace analysis of selected European medicinal plants. In Proceedings of the 12th International Congress of Flavours, Fragrances and Essential Oils, Vienna, Austria, Oct. 4.-8. 1992 (Woidlich, H. \& Buchbauer, G., eds.). Fachzeitschriftenverlags, Vienna, (1992), pp. 105-124.

5.- D. Grgesina, M. L. Mandic, L. Karuza, T. Klapec, D. Bockinac, Prehrambeno-tehnol. biotehnol. rev., 33, 111-113,(1995)

6.- B. Pekic, Z. Zekovic, A. Tolic, J. Serb. Chem. Soc., 60, 439-443,(1995)

7.- Z. Zekovic, B. Pekic, Z. Lepojevic, L. Petrovic, Chromatographia, 39, 587-590(1994).

8.- H.Vuorela, Y. Holm, R. Hiltunen, Application of headspace gas chromatography in essential oil analysis. Part VIII. Flavour Fragr. J., 4, 113-116(1989)

9.- H.Vuorela, Y. Holm, R. Hiltunen, T. Tarvela, A. Laitinen, Flavour Fragr. J., 5, 81-84,(1990)

10.- E.Reverchon, F. Senatore, J. Agric. Food Chem., 42, 154-158,(1994)

11.- B.Simandi, A. Kery, E. Lemberkovics, M. Oszagyan, E. Ronyai, I. Mathe, J. Fekete, E. Hethelyi, Supercritical fluid extraction of medicinal plants. In Process Technology Proceedings, 12. High Pressure Chemical Engineering. Proceedings of the 3rd International Symposium of High Pressure Chemical Engineering, Zürich, Switzerland, October 7-9, 1996 (von Rohr, Ph. R. \& Trepp, Ch., eds.). Elsevier, Amsterdam, (1996),pp. $357-362$.

12.- N.W.Davies, J. Chromatogr., 503, 1-24,(1990)

13.- P.R.Venskutonis, A.Dapkevicius, M.Baranauskiene, Flavour composition of some lemonlike aroma herbs from Lithuania. In Food Flavors: Generation, Analysis and Process Influence (Charalambous, G., ed.). Elsevier Science B.V., (1995);pp.833-847.

14.- P.Bradley, The British Herbal Compendium: Vol. 1: A Handbook of Scientific Information on Widely Used Plant Drugs. British Herbal Medicine Association, London, UK,(1993).

15.- C.A.Newall, L.A. Anderson, J.D. Phillipson, Herbal Medicines: a guide for healthcare professionals. Pharmaceutical Press, London,(1996).

16.- T. Shibamoto, . Retention Indices in Essential Oil Analysis. In: Capillary Gas Chromatography in Essential oil analysis. Edits., P.Sandra and C.Bicchi, (1987); pp. 259-274, Dr. Alfred Huethig Verlag, Heidelberg.

17.- N.W. Davies, J. Chromatogr.,503,1-24,(1990)

18.- R.P. Adams, Identification of essential oils by Ion trap Mass Spectroscopy. Academic Press, San Diego, CA(1989).

19.- M. T. Golmakani, K. Rezaei, Food Chem., 109, 925-930, (2008)a

20.- M. T. Golmakani, K. Rezaei, Eur. J. Lipid Sci. Technol., 110, 448-454, (2008)b

21.- E. E. Stashenko, B. E. Jaramillo, J. R. Martinez, J. Chromatogr. A, 1025, $105-113,(2004) \mathrm{a}$

22.- S. Rezvanpanah, K. Rezaei, S. H. Razavi, S. Moini, Food Sci. Technol. Res., 14, $311-314,(2008)$

23.- T. Özek, G. Özek, K. H. C. Baser, A. Duran, J. Essent. Oil Res., 17, 605 $610,(2005)$. 